\title{
In-situ kinetics study on the growth of expanded austenite in AISI 316L stainless steels by XRD
}

\author{
Zoltán Balogh-Michels, ${ }^{1, a)}$ Alexander Faeht, ${ }^{1,2}$ Simon Kleiner, ${ }^{2}$ Adrian von Känel, ${ }^{2}$ \\ Jean-Martin Rufer, ${ }^{2}$ Alex Dommann, ${ }^{1}$ Patrick Margraf, ${ }^{3}$ Gerhard Tschopp, ${ }^{2}$ \\ and Antonia Neels ${ }^{1}$ \\ ${ }^{1}$ Center for X-ray Analytics, Empa Swiss Federal Laboratories for Materials Science, Überlandstrasse 129, \\ 8600 Dübendorf, Switzerland \\ ${ }^{2}$ Institute for Applied Laser, Photonics and Surface Technologies ALPS, Bern University of Applied Science, \\ Quellgasse 21,2501 Biel-Bienne, Switzerland \\ ${ }_{3}^{3}$ Härterei Gerster AG, Güterstrasse 3, 4622 Egerkingen, Switzerland
}

(Received 24 April 2017; accepted 27 June 2017; published online 12 July 2017)

The formation of expanded austenite in $\mathrm{Cr}-\mathrm{Ni}$ austenitic stainless steels like AISI 316L is not completely understood despite its technological relevance. In this work, we present an in-situ $\mathrm{X}$-ray diffraction study on the growth kinetics of the expanded austenite. We applied a lowtemperature nitrocarburizing treatment using a mixture of $\mathrm{NH}_{3}, \mathrm{~N}_{2}, \mathrm{H}_{2}$, and $\mathrm{C}_{2} \mathrm{H}_{4}$ gases at atmospheric pressures in a novel and custom built chamber attached to a Bruker D8 Advance diffractometer. The nitrocarburizing temperature was varied between 340 and $440{ }^{\circ} \mathrm{C}$, and the possible effects of the gas amount were also tested. The thickness of the growing layer was determined from the shrinkage of the unmodified austenite peak. The growth rate coefficient was calculated using the linear-parabolic equation. The resulting coefficients follow the Arrhenius law with the activation energy of $165 \pm 12 \mathrm{~kJ} / \mathrm{mol}$. This value is in good agreement with the diffusion activation energy for heavy interstitials like carbon and nitrogen. The expanded austenite peak was modelled by a multilayer approach, where each $0.5 \mu \mathrm{m}$ sublayer has a constant lattice parameter. The lattice expansion is analyzed as a function of the Boltzmann-variable $\left(\eta=0.5 \times \mathrm{t}^{-1 / 2}\right)$. The expanded austenite layer in this metric has a constant width. Furthermore by rescaling with the lattice expansion of the first sublayer, it is possible to create a scale-independent master curve. These findings indicate that thickening of the expanded austenite is purely diffusion controlled, while the extent of strain is set by the uptake rate of the gas atoms. Published by AIP Publishing.

[http://dx.doi.org/10.1063/1.4993189]

\section{INTRODUCTION}

Gaseous nitriding/nitrocarburizing of stainless steel was for long regarded as a suboptimal solution, since the enhanced wear resistance is accompanied by a reduced corrosion resistance due to the formation of chromium nitride precipitates. In the 1980 s, by plasma nitriding at lower temperature a nitrogen supersaturation is achieved in austenitic steels ("S-phase"). ${ }^{1-3}$ In the meantime, the crystallographic nature of this phase has been unambiguously identified, i.e., it is a faulted fcc structure. ${ }^{4}$ Detailed information on the formation and the phase evolution is however lacking. ${ }^{5}$

This is especially true for the nitrocarburizing experiments, where the resulting structure is formed by interplay of $\mathrm{N}$ and $\mathrm{C}$ diffusion. Previous measurements established that the expanded austenite grows faster if both $\mathrm{C}$ and $\mathrm{N}$ are present (e.g., Refs. 6 and 7). In this case, two layers with more or less clear boundaries are formed. ${ }^{8-10}$ The thickness of the carbon expanded austenite and the nitrogen expanded austenite in a nitrocarburizing experiment is comparable to the respective carburizing or nitriding experiment. ${ }^{6,8}$ Irrespectively of the processing

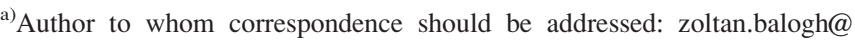
empa.ch. Tel.: +41587654864. Fax: +41587656954 .
}

sequence (simultaneous nitrocarburizing, carburizing followed by nitriding, nitriding followed by carburizing) the nitrogen expanded austenite occupies the surface and carbon expanded austenite occupies the deeper regions. ${ }^{6}$

The key challenge lies in the complex interplay of different physical phenomena. The usual strategy of applying $e x$-situ treatments and analyzing the specimen at different stages ${ }^{3,11,12}$ requires a favorable selection of heat treatment stages; otherwise, important information might be lost. One promising path is the application of in-situ measurement methods with good time resolution. This allows the division of the surface treatment process into elementary steps which can be studied in a well controlled manner. Such a strategy is proposed in, e.g., Ref. 5.

The solubility limit in the expanded austenite phase is very high [up to 38 at. \% (Ref. 13)] and composition varies as a function of time and depth. ${ }^{6,11}$ The boundary between the expanded austenite and the base material is sharp in most experiments. ${ }^{9} 11,14$ Based on the fact that diffusion is composition dependent and slower at low concentrations ${ }^{7,11}$ a sharp kinetic interface is indeed expected.

This sharp interface allows the determination of the layer thickness by X-ray diffraction using the Lambert-Beer attenuation law. Such a strategy was followed by Manova et al. to determine, among other parameters, the growth 
kinetics of the nitrogen expanded austenite into AISI 304 and AISI 316Ti steels using DC ion implantation. ${ }^{5,15}$ They observed that the growth rate coefficient is dependent on the treatment time as well as the applied ion current.

Typically, the diffusion process is the growth rate limiting step, but in some cases, the permeability of the interfaces or the nucleation of the new phases can be the bottleneck. ${ }^{16}$ The interface permeability or reaction rate limitation is especially common for solid-gas reactions. Indeed, the probably most well-known example of the reaction rate limitation is the thermal oxidation of $\mathrm{Si}^{17}$

In this work, we present our new reaction chamber. Using this setup, we measured the growth kinetics of the expanded austenite in thermochemically nitrocarburized AISI 316L stainless steel alloy by in-situ X-ray diffractometry (XRD). Even though the elementary diffusion steps are more complicated, we selected nitrocarburization as an example. We followed the total thickness of the expanded austenite by the shrinkage of the base material reflection. We also fitted the expanded austenite peak using a multilayer model.

\section{MATERIALS AND METHODS}

We used disc shaped specimens with a diameter of $15 \mathrm{~mm}$ and a height of $1.5 \mathrm{~mm}$ made of AISI 316L stainless steel delivered by L. Klein SA. Table I summarizes the alloying elements (weight \%) in the material [according to the industry standard; measured by glow discharge optical emission spectroscopy measurements (GD-OES); and XRFanalyzer Olympus Delta Pro DPO-2000-C].

The specimens are cut from $3 \mathrm{~m}$ long cold drawn rods, polished, and annealed at $1050^{\circ} \mathrm{C}$ for $10 \mathrm{~min}$ in a hydrogen atmosphere. XRD in the $30^{\circ}-100^{\circ}$ two theta range was done for the as-received samples (see supplementary material). The intensity ratios of the main peaks $(111,200,220,311$, and 222) do not deviate significantly from what is expected from a random oriented powder sample. These scans do not reveal the presence of preferred orientation normal to the specimen surface (i.e., the drawing direction). .

Finally, a thin Ni film is deposited on the surface immediately after argon sputtering to prevent the formation of a passivation layer which is known to be an impervious barrier for nitrogen. Similar specimens have been used by Christiansen and Somers. ${ }^{13,18}$ Based on the XRD diffraction
TABLE I. The composition of the AISI 316L specimen.

\begin{tabular}{lccccccccccc}
\hline \hline \multicolumn{1}{c}{$\mathrm{Cr}$} & $\mathrm{Ni}$ & $\mathrm{Mo}$ & $\mathrm{Mn}$ & $\mathrm{Si}$ & $\mathrm{Cu}$ & $\mathrm{N}$ & $\mathrm{P}$ & $\mathrm{C}$ & $\mathrm{S}$ & \\
\hline Ind. standard & $16-18$ & $10-14$ & $2-3$ & $<2$ & $<1$ & $<1$ & $<0.1$ & $<0.045$ & $<0.03$ & $<0.03$ \\
GD-OES & 16.8 & 11.8 & 2.2 & 1.5 & 0.7 & n.a & 0.03 & 0.03 & 0.02 & 0.02 \\
XRF & 16.9 & 11.1 & 2.0 & 1.5 & 0.7 & n.a & n.a & n.a & n.a & n.a \\
\hline \hline
\end{tabular}

patterns (see supplementary material) and the GD-OES data, this layer is about $0.1-0.15 \mu \mathrm{m}$ thick [see Figs. 5(a) and 5(b)].

For the in-situ investigations, a custom built reaction chamber constructed at the Bern University of Applied Science was used. The chamber was adapted to the X-ray diffractometer and allows XRD experiments to be carried out during chemical reactions. Figure 1 shows how the chamber is mounted in the Bruker D8 Advance goniometer (right side) and the peripheries.

A heater plug provides the high temperature. The sample is pressed against the heater plug by a spring (Fig. 2). The temperature is measured in the core of the specimen by a K-type thermocouple providing the feedback for the regulation circle. A second thermocouple was placed inside the heater plug and functioned as an overheat watch. This system shuts down the heating current in the case where the heater plug reached temperatures above $800^{\circ} \mathrm{C}$. The maximum sample temperature which can be achieved in this configuration is $550^{\circ} \mathrm{C}$. The final temperature is approached by a ramp of $20^{\circ} \mathrm{C} / \mathrm{min}$ on heating. The stability of the temperature in the holding stage is better than $\pm 3{ }^{\circ} \mathrm{C}$. The exact value however depends on the position of the specimen and the thermocouple within the specimen. The cooling of the specimen is aided by the water cooling circuit of the chamber. The specimen temperature reaches again ambient conditions within 5-10 min after the heating shut-off. This allows later $e x$-situ studies on well-defined samples.

The chamber can be operated with four different gases: $\mathrm{N}_{2}, \mathrm{NH}_{3}, \mathrm{H}_{2}$, and $\mathrm{C}_{2} \mathrm{H}_{4}$ in a flow mode. $\mathrm{N}_{2}, \mathrm{NH}_{3}$, and $\mathrm{H}_{2}$ are mixed together before being introduced into the chamber. Ethene is supplied by a second pipeline (see Fig. 3 for the diagram of the gas supply system). Nitrogen itself is an inert gas; it is used to purge the system or to add a nonreactive component to the gas mixture. Ammonia is the supplier for $\mathrm{N}$ atoms and ethene is the supplier of $\mathrm{C}$ atoms. Thus, this system allows nitriding, carburizing, and nitrocarburizing
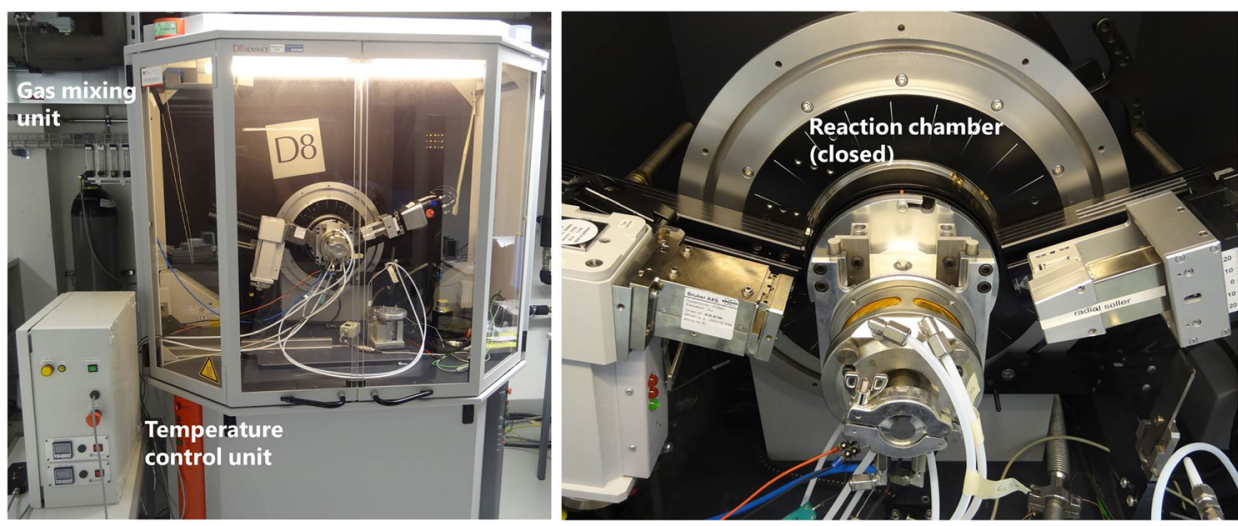

FIG. 1. Reaction chamber mounted on the BRUKER D8 diffractomer for in-situ studies. 


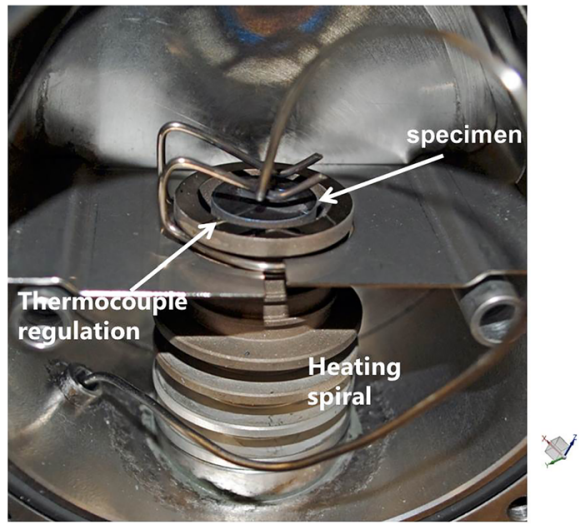

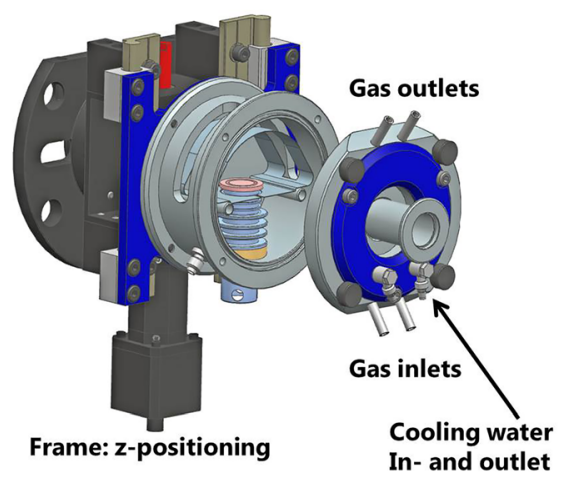

FIG. 2. The measurement chamber with a specimen mounted and the $C A D$ view of the reaction chamber. with different $\mathrm{N}$ and $\mathrm{C}$ supply levels. Since there is an inert gas option, the system can also be used for other purposes.

To allow X-ray transparency, the sidewalls of the chamber are made of a thin Kapton-foil. Consequently, only atmospheric pressure is allowed inside the chamber. The maximum allowed flow is $8 \mathrm{l} / \mathrm{h}$ for both supply lines. Since some of these gases are either flammable or corrosive, a constant pumping of the chamber is required. Due to the low amount of gases, this can be achieved by the exhausts of the XRD system itself.

During an experiment, the chamber is first purged with inert gas $\left(\mathrm{N}_{2}\right)$ while the temperature is set. When the set temperature is reached, the nitrogen content is reduced while the amount of reactive gases is increased. This allows a better control of the reaction start.

The sample is fixed by a clamp, and its z-position can be adjusted by a motor. The specimen height was optimized to achieve the highest XRD signal for the (111) peak of the $\gamma$ Fe phase. The specimens used in the experiments had a hole for the thermocouple.

The XRD instrument is a Bruker D8 Advance system with a Vantec-1 position sensitive detector. The X-ray source is a sealed tube $\mathrm{Cu} \mathrm{K} \alpha$ source at an acceleration voltage of $40 \mathrm{kV}$ and an electron current of $40 \mathrm{~mA}$. The beam was shaped by a Göbel-mirror, i.e., a parallel beam setup was used. The Fe fluorescence is suppressed by the combination of a Ni K $\beta$ filter and a high discriminator voltage. This combination ensured the best possible signal to noise ratio

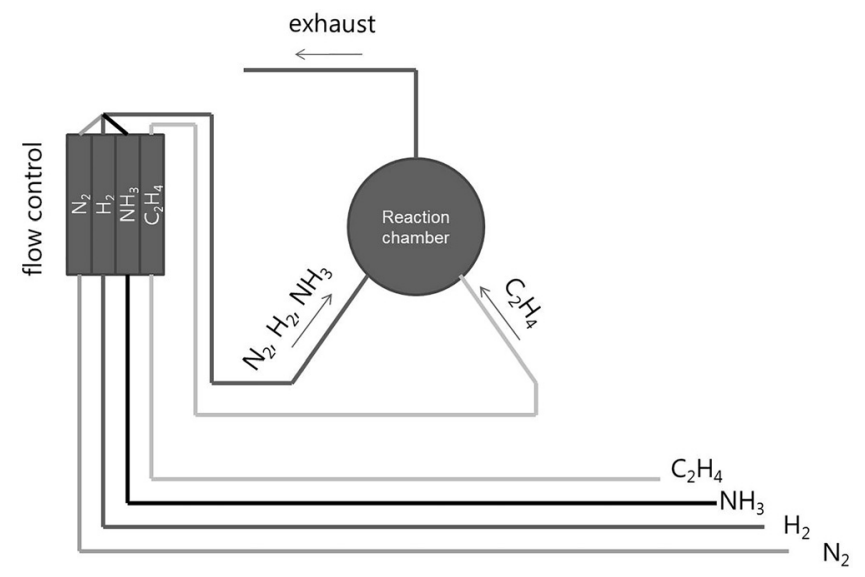

FIG. 3. The schematic drawing of the gas supply system. (within the limits of the $\mathrm{Cu} \mathrm{K} \alpha$ source). We collected data in the $35^{\circ}-45^{\circ} 2 \Theta$ range. This contained the highest intensity (111) peak of the $\gamma$-Fe phase from the base material (around $43.3^{\circ}$ depending on the exact processing temperature) as well as the same reflection of the expanded austenite being formed during the in-situ investigation at slightly lower angles. The collection time varied with respect to the state of the specimen. In the beginning when the peak intensity is high and the rate of change is rapid, detector movements up to $10^{\circ} / \mathrm{min}$ have been used. In the later stages, it has been reduced to $0.5^{\circ} / \mathrm{min}$ for a better signal to noise ratio.

To investigate the activation parameters, we carried out heat isothermal treatments at $340,360, \ldots, 440^{\circ} \mathrm{C}$ using $2.51 / \mathrm{h}$ $\mathrm{N}_{2}, 1.5 \mathrm{l} / \mathrm{h} \mathrm{NH}, 1.5 \mathrm{l} / \mathrm{h} \mathrm{H} \mathrm{H}_{2}$, and $0.15 \mathrm{l} / \mathrm{h} \mathrm{C}_{2} \mathrm{H}_{4}$ flows. To observe the effects of the $\mathrm{NH}_{3}$ supply, we carried out isothermal heat treatments at $380{ }^{\circ} \mathrm{C}$ at different gas flows $(3.75 \mathrm{l} / \mathrm{h}$ $\mathrm{N}_{2}, 2 \mathrm{l} / \mathrm{h} \mathrm{NH}_{3}, 2 \mathrm{l} / \mathrm{h} \mathrm{H}_{2}$, and $0.2 \mathrm{l} / \mathrm{h} \mathrm{C}_{2} \mathrm{H}_{4} ; 1.5 \mathrm{l} / \mathrm{h} \mathrm{N} \mathrm{N}_{2}, 1.0 \mathrm{l} / \mathrm{h}$ $\mathrm{NH}_{3}, 1.0 \mathrm{l} / \mathrm{h} \mathrm{H}$, and $1 \mathrm{l} / \mathrm{h} \mathrm{C}_{2} \mathrm{H}_{4}$; and $2.5 \mathrm{l} / \mathrm{h} \mathrm{N} \mathrm{N}_{2}, 1.0 \mathrm{l} / \mathrm{h} \mathrm{NH}_{3}$, $1.0 \mathrm{l} / \mathrm{h} \mathrm{H}_{2}$, and $0.1 \mathrm{l} / \mathrm{h} \mathrm{C}_{2} \mathrm{H}_{4}$ ).

Our approach of the nitrocarburizing process is similar to the one proposed by Christiansen and Somers. ${ }^{18}$ The main advantage of a thermochemical treatment as compared to the plasma treatment is the better control over the resulting material. In a pure chemical reaction, the rate of nitrogen accumulation is driven by the chemical potential difference between the ammonia and the dissolved nitrogen. This means that the ammonia partial pressure/flow rate determines the nitrogen uptake. ${ }^{19}$ Similarly, the partial pressure of ethene controls the carbon uptake.

To gain information on the distribution of $\mathrm{C}$ and $\mathrm{N}$, glow discharge optical emission spectroscopy measurements (GDOES) have been carried out. GD-OES employs a capacitively coupled low pressure glow discharge, where the sample is used as the cathode and a copper tube is used as the anode. The sample material is sputtered by the bombardment of accelerated fast ions. The sputtered atoms diffuse into the plasma region of the discharge, situated inside the tubular anode. Here, they are excited by shock and/or ionised. The subsequent emission of photons allows their detection by means of an optical spectrometer and therefore allows for quantification of the content depth profiles. The layer by layer sputtering of the sample with a depth resolution of a few $\mathrm{nm}$ and a sputtering rate in the order of $10-100 \mathrm{~nm} \times \mathrm{s}^{-1}$ allows for relatively high sample throughput rates. 
The GD-OES unit at the Bern University of Applied Sciences is a Spectruma GDA750 instrument equipped with a RF generator capable of supplying constant real power, constant applied RF-voltage, or constant DC-bias voltage and also capable of being operated with continuous or pulsed $\mathrm{RF}$ power. In this measurement, $30 \mathrm{~W}$ RF power was applied. Before the measurement, the system was evacuated to $1.7 \mathrm{~Pa}$ base pressure, while during the measurement, $350 \mathrm{~Pa} \mathrm{Ar}$ gas was applied. The sputtering rate was assumed to be constant, and it was determined by measuring the final crater depth with a Mahr MarSurf M400 profilometer and dividing the depth by the total sputtering time. Recalibration of the GDOES system was done before each series of measurement and the following certified calibrations standards were used: JK 49, NSB 1766, MBH NSB3, S25, and S26.

For the determination of the final expanded austenite layer thickness, the cross sections of the specimens were metallographically analyzed after completion of the in-situ experiments. The discs were cut in half by use of PRESI S-type cut-off-wheels and embedded in thermosetting epoxy resin at $180^{\circ} \mathrm{C}$ and a compression force of $20 \mathrm{kN}$ for $9 \mathrm{~min}$ on a STRUERS LABOPRESS-3. Subsequently, the cross section of each specimen was ground on a PRESI MECAPOL P230 and polished on a STRUERS TEGRAMIN-25. Grinding and polishing were carried out at 10 grain size stages, starting with P240 abrasive paper and finishing with $1 \mu \mathrm{m}$ diamond suspension. Each of the 10 steps was performed for $3 \mathrm{~min}$. The polished metallographic specimens were wiped for $4 \mathrm{~s}$ with absorbent cotton soaked in Adler's Reagent. Finally, images of the etched specimens were captured by means of a NIKON ECLIPSE LV150 optical microscope.

\section{THEORY AND CALCULATION}

\section{A. Layer thickness determination}

Figures 4(a) and 4(b) show examples of specimens after the metallographic analysis. The expanded austenite layer is clearly visible and a sharp interface appears between the base material and the processed region. This interface and the specimen edge are used as the references for the parallel distance measurement in order to estimate the expanded austenite layer thickness. Hardness measurements were carried out with a Fischerscope HM2000 indentation hardness tester with a test force of $150 \mathrm{mN}$ using a standard Vickers pyramid. They revealed the improved hardness [Fig. 4(c)] as a result of the nitrocarburizing treatment.

The thickness of the layer is determined using the attenuation of the signal, in a manner which has been proposed in Ref. 5. Assuming a sharp interface between the base material and the expanded austenite layer, the attenuation of the signal from the base material can be calculated using the Lambert-Beer law

$$
I(x+\Delta x)=I(x) \exp (-\lambda \Delta x),
$$

where $I(\mathrm{x})$ and $I(\mathrm{x}+\Delta \mathrm{x})$ are the intensities in the case of a layer with thickness $x$ and $x+\Delta x$, and $\lambda$ is the attenuation coefficient. It is possible to select $\mathrm{x}=0$; however, this particular selection holds no fundamental advantage. Indeed, since it is

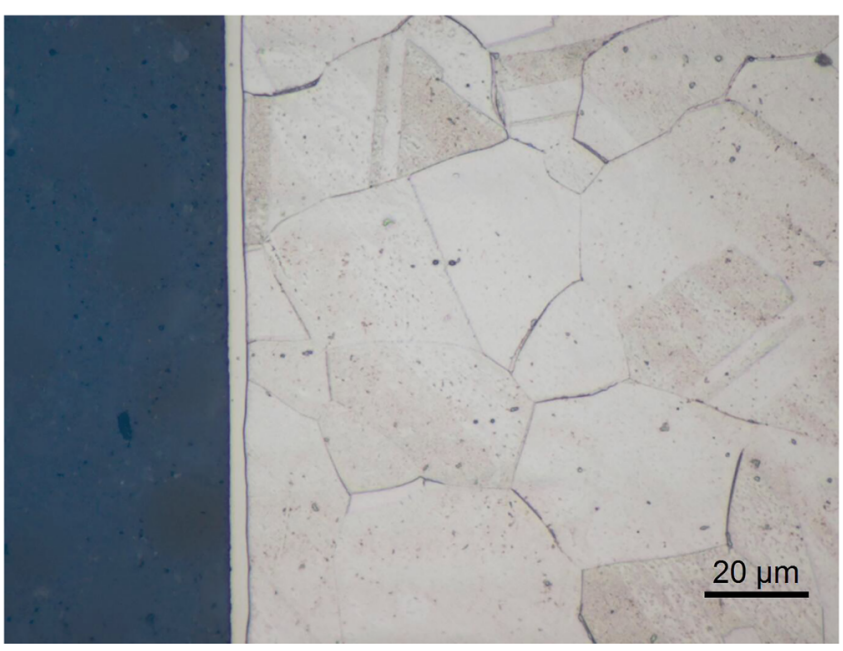

(a)

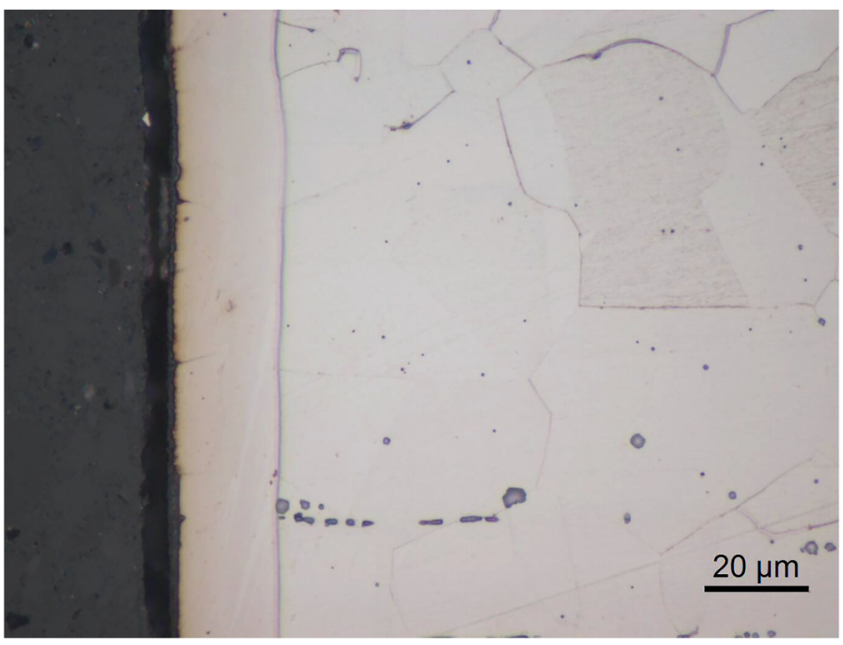

(b)

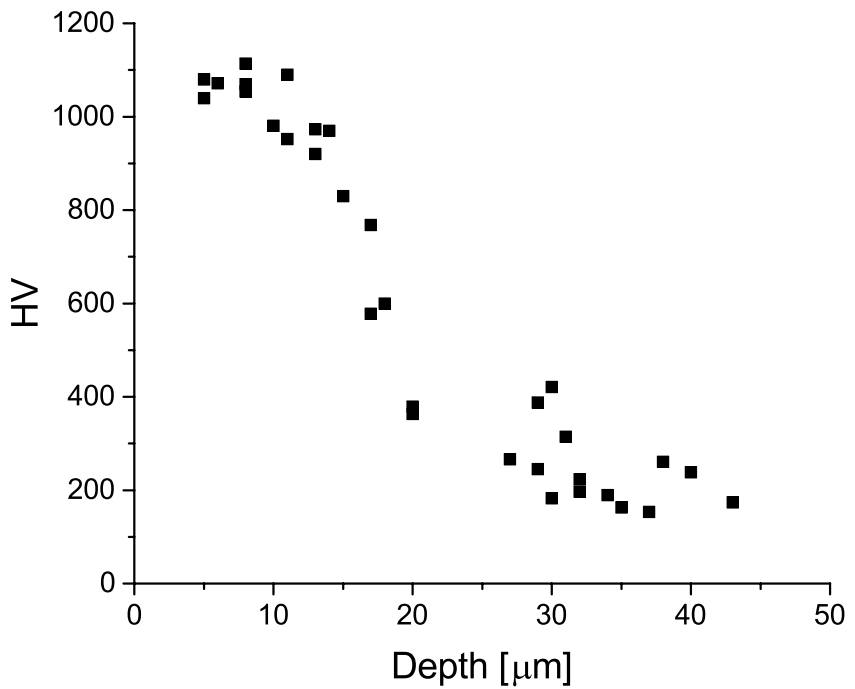

(c)

FIG. 4. Cross section of a specimen treated with $2.5 \mathrm{l} / \mathrm{h} \mathrm{N} \mathrm{N}_{2}, 1.5 \mathrm{l} / \mathrm{h} \mathrm{NH} \mathrm{NH}_{3}, 0.15 \mathrm{l} / \mathrm{h}$ $\mathrm{C}_{2} \mathrm{H}_{4}$, and $1.5 \mathrm{l} / \mathrm{h} \mathrm{H} \mathrm{H}_{2}$ at $400^{\circ} \mathrm{C}$ for $90 \mathrm{~min}$ (a) and with the same gas mixture at $500{ }^{\circ} \mathrm{C}$ for $210 \mathrm{~min}$ (b). The interface between the base material and the expanded austenite phase is sharp. The thickness of the expanded austenite is $3.3 \pm 0.5 \mu \mathrm{m}$ and $19.5 \pm 0.5 \mu \mathrm{m}$. The substrate phase appears blurred, because it is partially below the focal plane, due to its relatively low resistance to the abrasive processing compared to the expanded austenite phase. (c) Vickers hardness depth profile $(150 \mathrm{mN}$ applied force) of the specimen from (b). Each point represents a singular measurement, and the scatter of the data indicates the measurement error. 
highly unlikely that the interface between the expanded austenite and the base material is atomically sharp, an arbitrary, intermediate " $t=0$ " where the reaction front is already established is a more sensible choice. The absolute length scale was determined with the help of metallographic analysis and the GD-OES depth profile $\left(\lambda \approx 0.67 \mu \mathrm{m}^{-1}\right)$. This value is in general agreement $(<10 \%$ difference) with that of Ref. 5. Attenuation coefficient calculations were carried out using the data in the NIST Databank, and the difference between the base alloy and different $\mathrm{N}$ - and C-expanded austenite agreed each other with $5 \%$ (see supplementary material). Since the expanded austenite peak is rather broad, the angle dependence of the attenuation coefficient could have also been taken into account (again in the $<5 \%$ from the highest lattice expansion to the base material). To make a precise enough calculation which justifies the extra complications, a detailed knowledge of the expanded austenite phase would have been a requirement. Therefore, we accepted a possibility of $\pm 10 \%$ error in our evaluation. The possible changes in the Ni layer are neglected, as this layer is very thin as compared to the information depth.

In the simplest case of pure diffusion controlled reaction, the thickness of the layer will be proportional to the square root of the processing time according to Fick's law. This is however not always true, for solid state reactions other bottlenecks can control the reaction rate at the nanoscale (e.g., Ref. 20). For a reaction with a gaseous medium, this can be observed even at the macroscopic scale. ${ }^{17}$

For such cases, the so-called linear parabolic growth law can be applied. ${ }^{21}$ The thickness of the layer $(x)$ can be given by the following formula:

$$
t-t_{0}=\frac{x^{2}}{2 \tilde{D}}+\frac{x}{k},
$$

where $t$ is the time, $t_{0}$ is the incubation time, $\tilde{D}$ characterizes the diffusion limit (parabolic), while $k$ characterizes the supply/interface limited (linear) growth. While $\tilde{D}$ is not the interdiffusion coefficient in the strictest sense, they are similar as both measure the net broadening of the diffusion/reaction zone. Also, the $k$ supply rate covers different supply limitations, the actual partial pressure (chemical potential) of the reactive gases, the chemical reaction at the surface (e.g., $\mathrm{NH}_{3} \rightarrow \mathrm{N}+3 \mathrm{H}$ ), and even the permeability of the surface/ surface barrier. ${ }^{22} t_{0}$ contains the influence of the nucleation difficulties as well as some measurement uncertainties, i.e., when exactly the gas pressure and the temperature reach stable conditions. This parameter thus allows the elimination of the effect of the initial transients.

More interesting is the interplay of $\tilde{D}$ and $\mathrm{k}$. If $\mathrm{x} \ll \tilde{D} / k$, the function has a linear character, while if $\mathrm{x} \gg \tilde{D} / k$, the function is parabolic. These cases allow an easy determination of the $k$ and $\tilde{D}$ rate constants, respectively. However, if $\mathrm{x} \approx \tilde{D} / k$ both coefficients are required for the complete characterization. Neglecting this behavior would lead to a time dependent diffusion coefficient, as it was observed in Ref. 5.

\section{B. Modelling the expanded austenite}

Using the total thickness of the expanded austenite as an input parameter, the deconvolution of the broad, asymmetric peak can be attempted. Depth profiles have been determined by Öztürk and Williamson. ${ }^{23}$ In their work, they used actual ion beam sputtering to carry out XRD measurements at different depths. The sample is then modelled as a multilayer, where each layer has a characteristic composition. The signal from each layer is attenuated by the layer on the top of them.

We used a simple model based on the following assumptions:

- The sublayers are $0.5 \mu \mathrm{m}$ thick.

- The lattice parameter within one sublayer is constant.

- The peak shapes are Gaussian.

- The peak broadening within each sublayer is negligible as compared to the instrumental peak width $\left(0.13^{\circ}-0.17^{\circ}\right)$.

- The peak areas are following the exponential attenuation law (difference in the angles is small enough).

- The total intensity of the expanded austenite peak is equal to the intensity loss of the base material peak. Manova et al. have found that the sum of the two peaks is practically constant during the processing. ${ }^{15}$

- The only free variable is the peak position, i.e., the lattice parameter.

- There is a bijection between a lattice expansion $(\Delta d)$ and the interstitial concentration $(c)$, and the relationship does not have to be a simple proportionality between the two, but $\varepsilon \leftrightarrow c$.

- The possible changes in the $\mathrm{Ni}$ layer are assumed to have a negligible influence (the total thickness is below $0.2 \mu \mathrm{m})$.

This means that for, e.g., a state with $1.5 \mu \mathrm{m}$ expanded austenite thickness, the $\gamma_{\mathrm{N}}$ peak is modelled as a sum of three peaks with an area ratio of 1:0.716:0.513. While this method is far from being a high precision technique, it nevertheless delivers interesting information on the formation of the expanded austenite layer.

The composition profile during the phase growth is usually plotted as $c(\mathrm{x}, \mathrm{t})$, where $x$ is the depth and $t$ is the time. However, for a purely diffusive process, the single variable $\eta=0.5 x t^{-1 / 2}$ is sufficient to describe the profile (Boltzmanntranformation $\left.^{24}\right)$. The resulting diffusion equation for this case is

$$
-2 \eta \frac{d c}{d \eta}=\frac{d}{d \eta}\left[D(c) \frac{d c}{d \eta}\right]
$$

This means that the concentration is a function of only $\eta$, i.e., the concentration contours expand following a parabolic growth rate. Note that while the exact shape of the composition profile depends on the concentration dependence of the diffusion coefficient, the parabolic expansion rate is nevertheless fulfilled for any given $c$ as long as the continuum diffusion laws are applicable. If the diffusion coefficient shows an extreme (4-10 orders of magnitude) concentration difference, gradients exceeding the 100 at. \% per atomic planes might be required by the continuum diffusion equations in nanoscale diffusion experiments. ${ }^{25,26}$ Since in this experiment we used XRD, a method with micrometer range penetration depth, these effects cannot play any role. 
Accordingly, if there is a time dependence of $\Delta d(\eta)$ it must have a non-diffusion related origin.

In this simple model, we did not include the influence of the stress, even though its role is one of the key problems in the field, e.g., Ref. 27. Stress is surely a very important factor as it changes the chemical potential of the system as well as through the activation volume the diffusivity itself. However, it is also known that stress effects have no influence on the behavior of the atomic transport (i.e., the Fickian-diffusion laws are still valid, though with a different interdiffusion coefficient). ${ }^{28}$ Therefore, at the level of this qualitative model, we do not have to include stress generation and accommodation.

\section{RESULTS AND DISCUSSION}

\section{A. Kinetics and total expanded austenite thickness}

Figure 5 shows two typical GD-OES depth profiles, the first one is for $340^{\circ} \mathrm{C}$ processing temperature, while the second one is for $380{ }^{\circ} \mathrm{C}$ where the expanded austenite is more developed. The element distributions match the literature observations, i.e., that nitrogen supersedes carbon and pushes the $\mathrm{C}$ atoms to the deeper regions. ${ }^{6}$ The transitions between the Ni layer, the expanded austenite, and the base material are well observable. For a better separation of the heavy metallic and light interstitial elements, we plotted the weight $\%$ as shown in Figs. 5(a) and 5(b). The atomic \% of the light interstitials is plotted in Figs. 5(c) and 5(d).

Figure 6(a) shows a typical XRD pattern from an intermediate stage at $380{ }^{\circ} \mathrm{C}$ with a normal gas flow. Both the (111) peaks of the base material and the expanded austenite are visible. The peak of the expanded austenite is very broad and asymmetric. Other examples are also shown in the supplementary material; in some cases, even the separation of the $\mathrm{C}$ - and $\mathrm{N}$-expanded austenite might be possible.

Figure 6(b) shows the evolution of the signal in the same experiment. The decrement of the base material peak as well as the growth of the expanded austenite peak is clearly visible. In the same time, the peak of the expanded austenite shifts towards lower Bragg-angles (higher lattice parameters) as a consequence of the carbon/nitrogen uptake. This peak will be analyzed in detail in Sec. IV B.

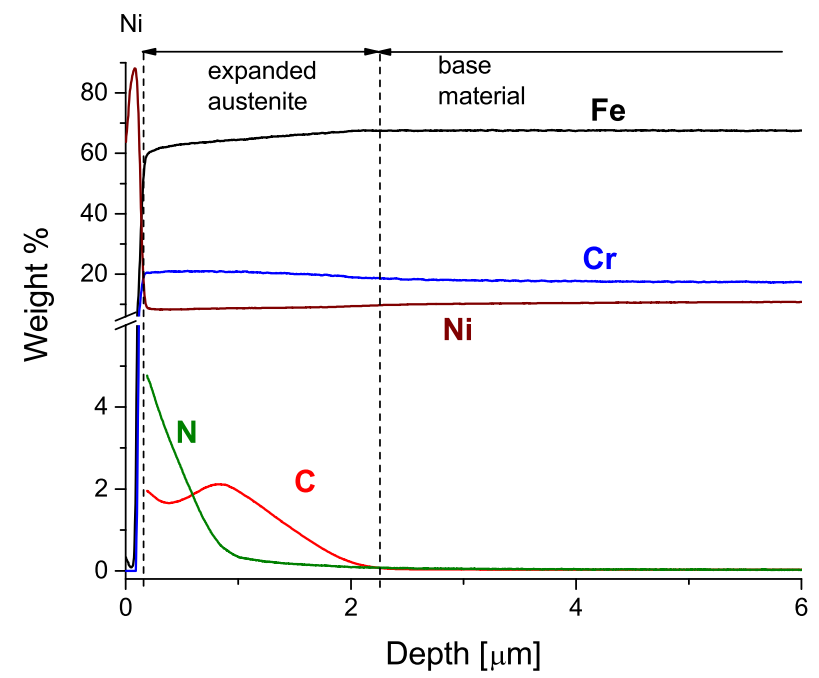

(a)

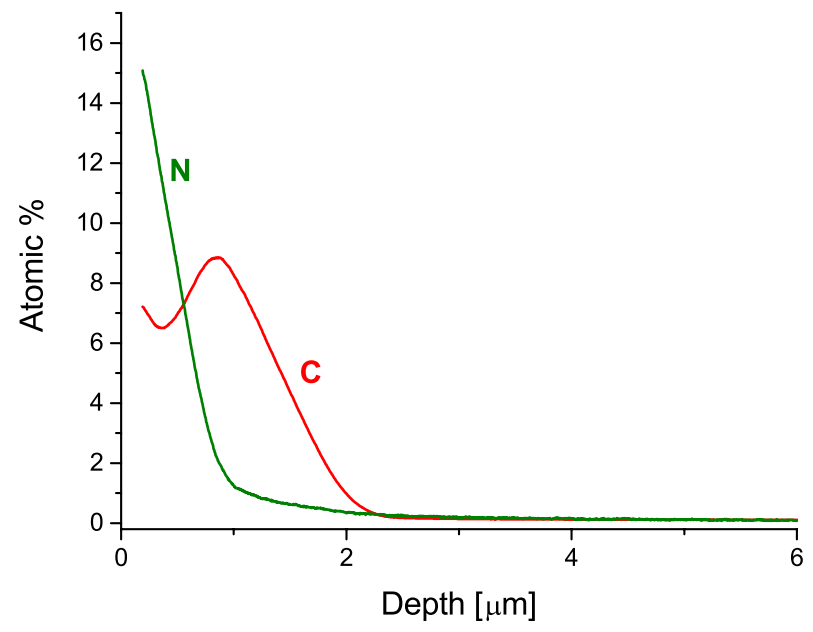

(c)

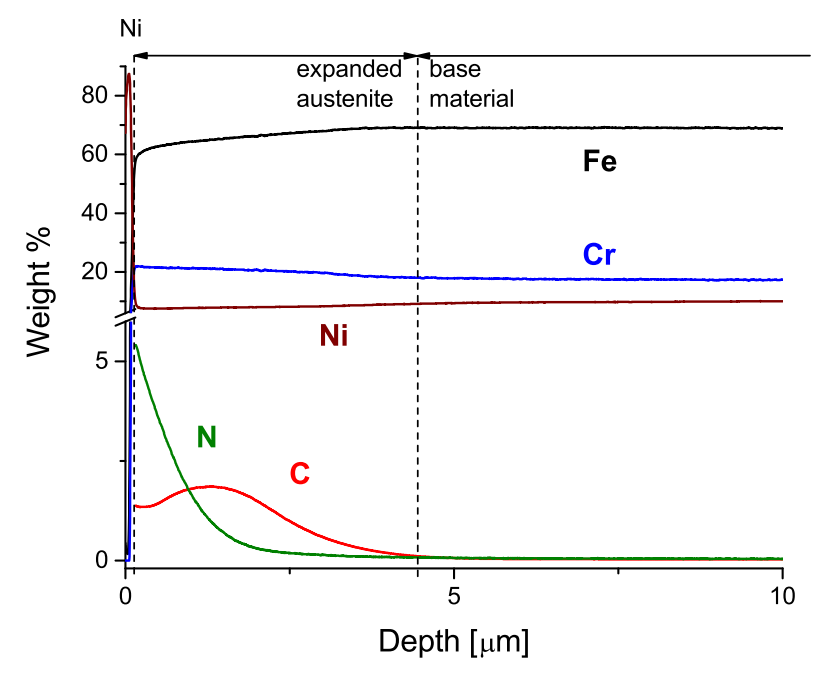

(b)

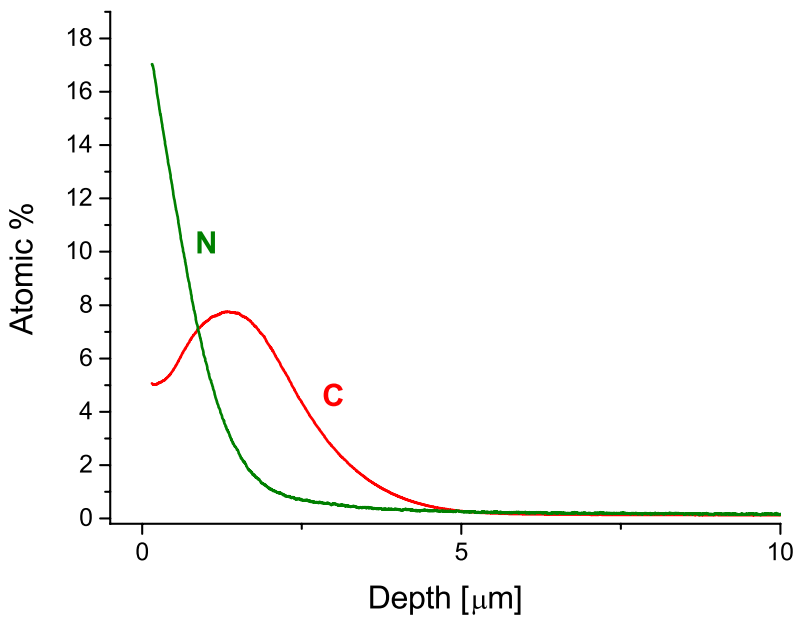

(d)

FIG. 5. Typical GD-OES depth profiles, weight $\%$ of both the metallic and the interstitial elements after the $340^{\circ} \mathrm{C}$ (a) and the $380{ }^{\circ} \mathrm{C}$ normal gas flow processing (b). Atomic $\%$ of the light interstitial elements of the respective nitrocarburizing treatments (c) and (d). 


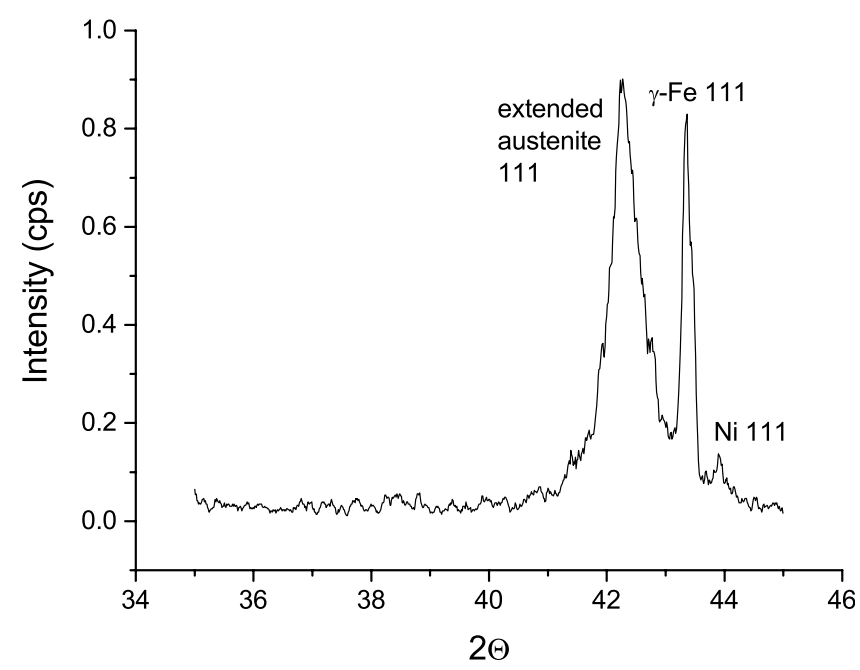

(a)

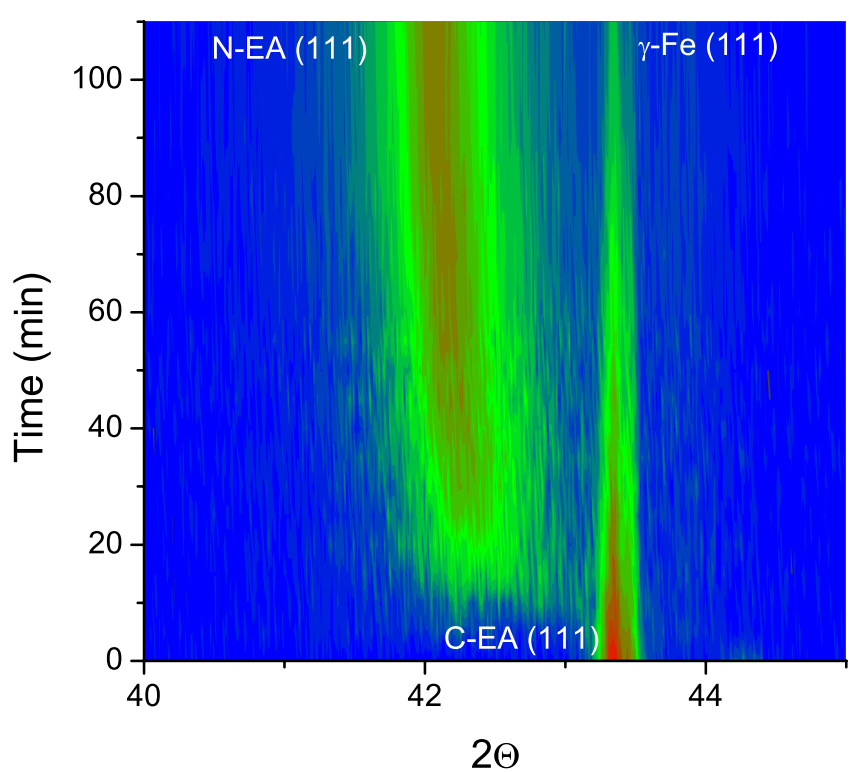

(b)

FIG. 6. (a) Typical XRD pattern from an intermediate step. (b) The evolution of the XRD patterns, first the C-expanded austenite appears, later peak shifts towards lower angles (the $\mathrm{N}$-expanded austenite) as the nitrocarburizing progresses.

The square of layer thickness for the $400{ }^{\circ} \mathrm{C}$ processing, calculated from Eq. (1), is plotted as a function of time on Fig. 7(a). It can be seen that that the linear relationship, indicating diffusion controlled growth, is not exactly fulfilled from the beginning. The derived rate coefficient is $7.2 \times 10^{-15} \mathrm{~m}^{2} \mathrm{~s}^{-1}$.

In Fig. 7(b), the same data are plotted using the model of Eq. (2). An almost perfect fit is achieved and the rate coefficient for the diffusion controlled part is slightly higher $1.2 \times 10^{-14} \mathrm{~m}^{2} \mathrm{~s}^{-1}$. These growth rate coefficients are higher than the ones measured by Manova et al. ${ }^{5}$ during plasma nitriding of AI316Ti alloys at $400^{\circ} \mathrm{C}$. The comparison of the data with those reported by Christiansen et al. ${ }^{7,11}$ is not as straightforward as the key result of this work was the composition dependence of the diffusion coefficient. Comparing their composition dependence curve (Fig. 2 in Ref. 11) with our values, there is about one order of magnitude difference in this

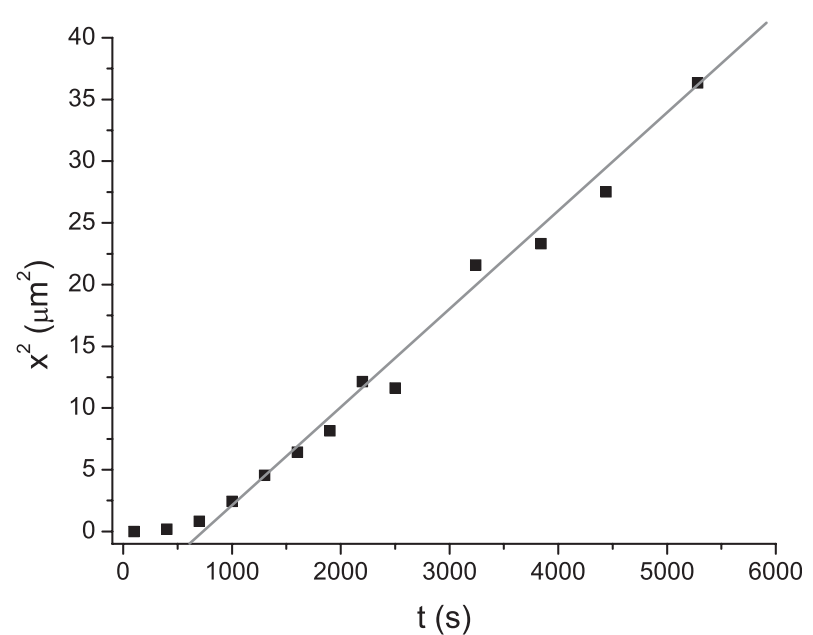

(a)

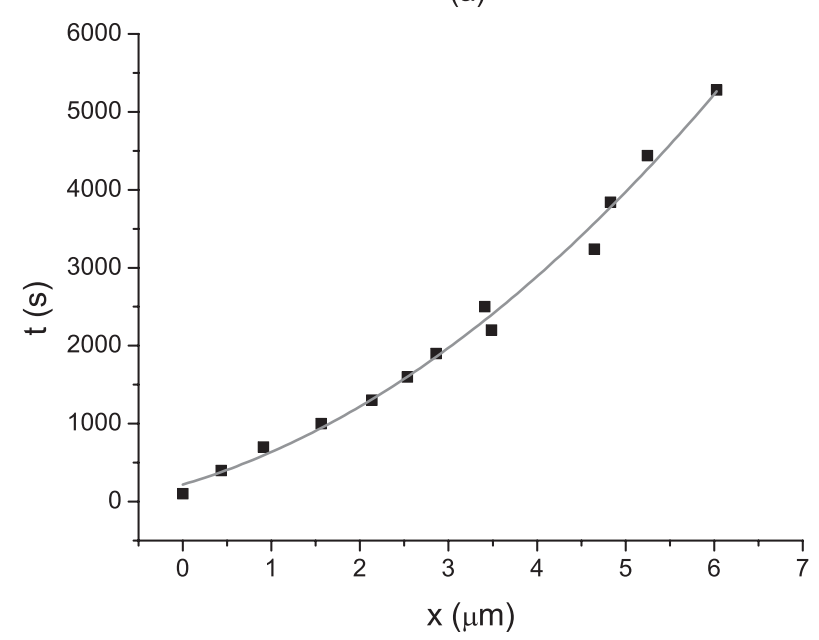

(b)

FIG. 7. The evolution of the layer thickness for the $400{ }^{\circ} \mathrm{C}$ processing plotted in two different manners. (a) The standard $x^{2} \sim t$. The grey line indicates a fit on the later stages of the process. (b) Linear-parabolic fit on the data.

case too. It is well known that in the case of nitrocarburizing, the expanded austenite grows faster, and according to Ref. 6, the carbon expanded austenite and the nitrogen expanded austenite grow more or less independently of each other.

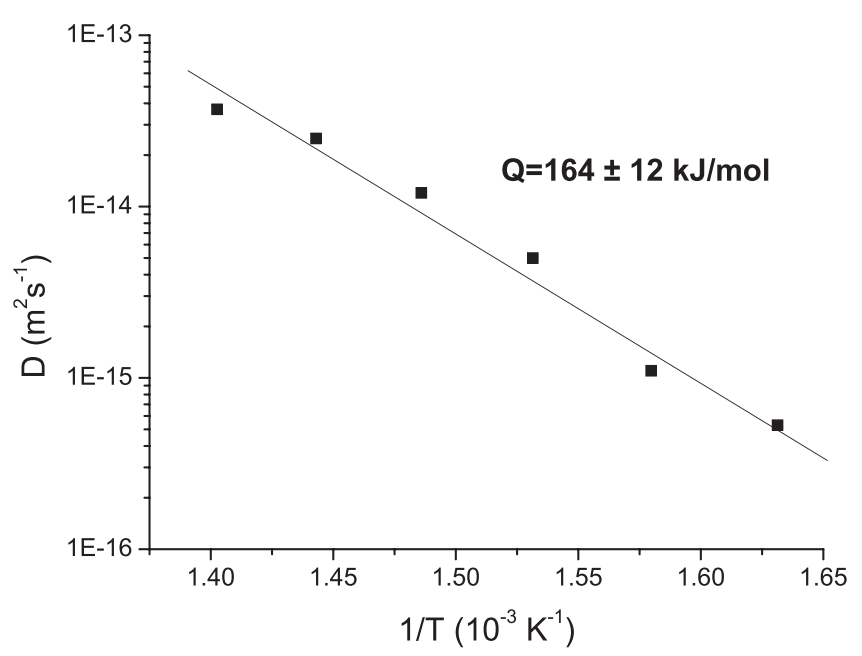

FIG. 8. Arrhenius-plot of the growth coefficients. The best fit of the data is achieved by an activation energy of $165 \pm 12 \mathrm{~kJ} / \mathrm{mol}$. 


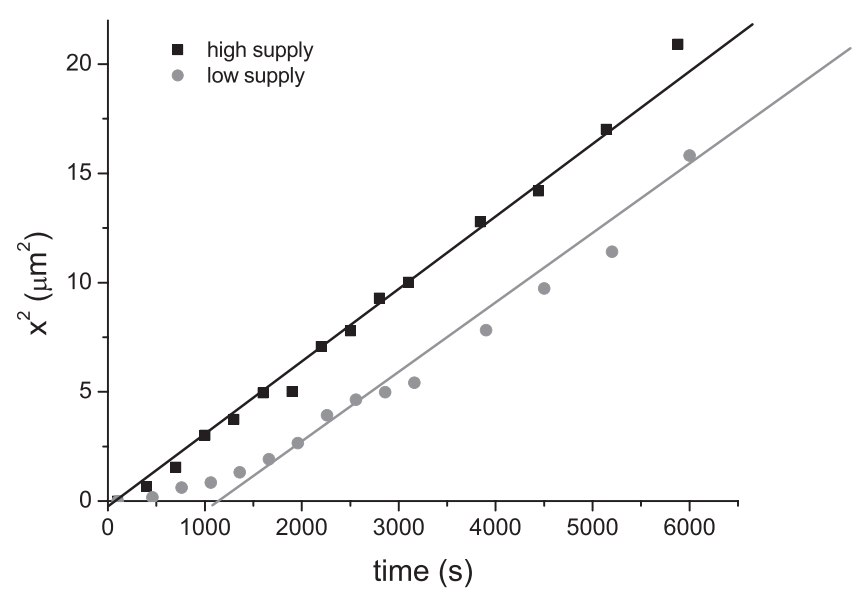

FIG. 9. Comparison of the growth in the case of the "high" $\left(3.751 / \mathrm{h} \mathrm{N}_{2}, 21\right.$ / h NH $3,21 / \mathrm{h} \mathrm{H}_{2}$, and $\left.0.2 \mathrm{l} / \mathrm{h} \mathrm{C}_{2} \mathrm{H}_{4}\right)$ and "low" (1.5 l/h N $\mathrm{h}_{2}, 1.0 \mathrm{l} / \mathrm{h} \mathrm{NH}_{3}, 1.0 \mathrm{l} / \mathrm{h}$ $\mathrm{H}_{2}$, and $\left.11 / \mathrm{h} \mathrm{C}_{2} \mathrm{H}_{4}\right) \mathrm{NH}_{3}$ gas flow. The processing temperature was $380{ }^{\circ} \mathrm{C}$ in both cases.

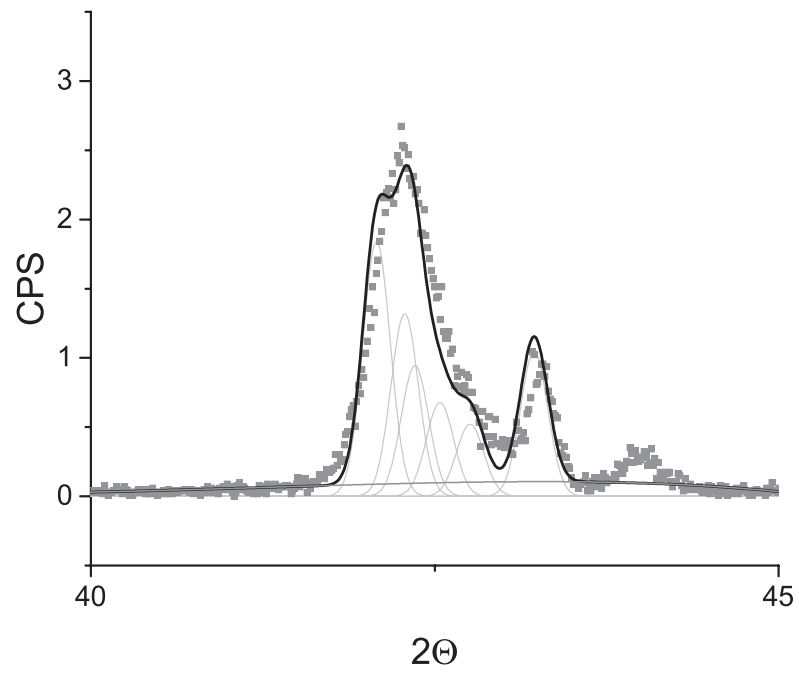

(a)

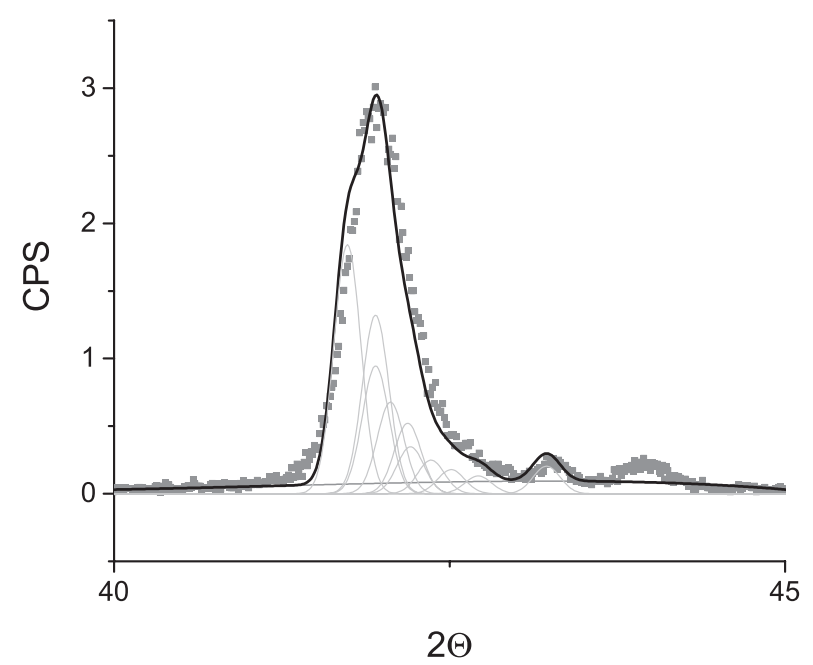

(c)
Figure 8 is the Arrhenius plot of the growth rate coefficients, while there is some scatter a linear fit with an activation enthalpy for the growth of the expanded austenite $164 \pm 12 \mathrm{~kJ} / \mathrm{mol}$ describes the experimental data well. Williamson et al. determined an activation energy of $140 \mathrm{~kJ} /$ mol in the case of plasma nitriding. ${ }^{3}$ The activation energy of $\mathrm{N}$ interstitial diffusion in $\gamma-\mathrm{Fe}$ is $157 \mathrm{~kJ} / \mathrm{mol}$ according to Smith. $^{29}$ These agree within the margin of error with our results. A publication by Thibaux et al. not only presents their result on the C-diffusion in austenite ${ }^{30}$ but presents a brief literature summary on the topic too. ${ }^{31,32}$ Our growth rate coefficients are more than two orders of magnitude higher than the $\mathrm{C}$ diffusion coefficients in these papers. In the literature, it is discussed that the presence of $\mathrm{N}$ accelerates the $\mathrm{C}$ diffusion, as $\mathrm{N}$ occupies the possible trapping sites (e.g., Ref. 6). Therefore, a faster $\mathrm{C}$ diffusion would not be surprising.

Figure 9 shows the square of the layer thickness as a function of the time for the examples of "high" and "low" gas supply. For high gas supplies, the diffusion controlled

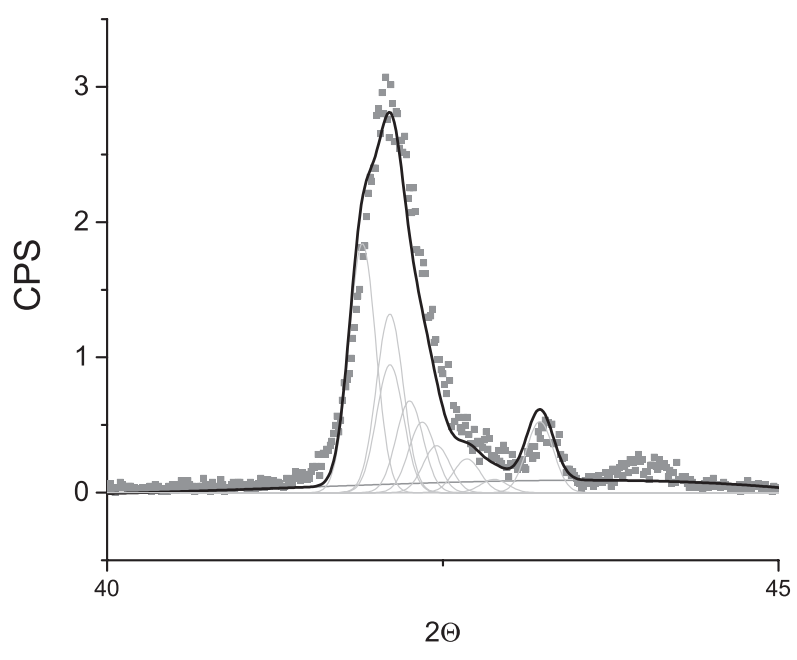

(b)

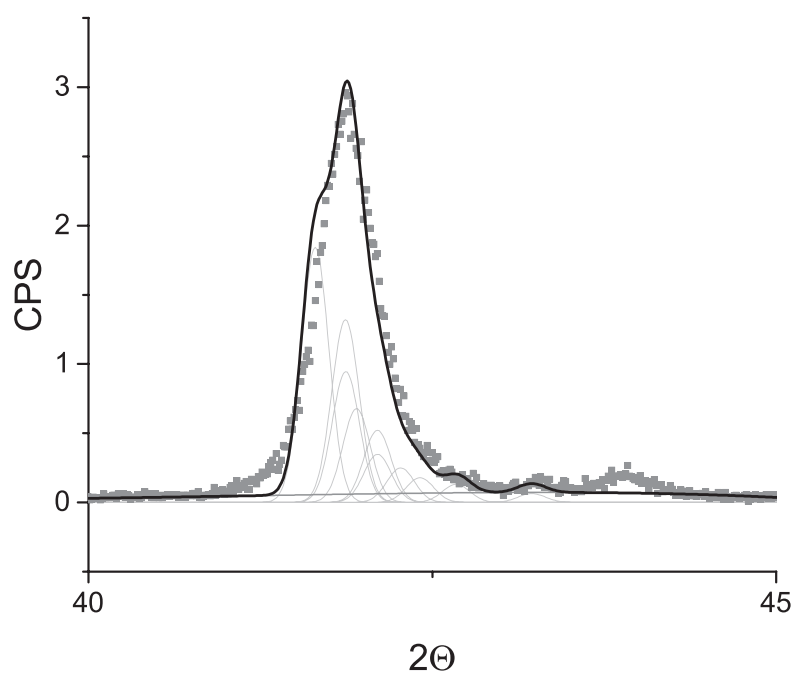

(d)

FIG. 10. Examples of the fitting results (measurement data: $420^{\circ} \mathrm{C}, 15,30,50$, and $70 \mathrm{~min}$ ). The thin lines represent the background as well as the singular Gaussians, and the thick line is the sum. While the agreement is not perfect, the qualitative features of the peak are reproduced. 
regime $\left(x^{2} \sim t\right)$ is established immediately at the beginning of the process, while a well-observable time lag is visible for the low gas supply case. This indicates that for lower gas amount, the growth might be limited by the gas supply and not the bulk diffusion. For a detailed analysis of the "reaction/interface barrier" control case, ${ }^{17}$ the present dataset is not detailed enough. Further investigations are planned for a more precise analysis.

If we evaluate the rate coefficients according to the linear-parabolic equation, we end up with very similar results without a clear tendency for the parabolic rate coefficients $\left(4.0 \times 10^{-15} \mathrm{~m}^{2} \mathrm{~s}^{-1}, 3.6 \times 10^{-15} \mathrm{~m}^{2} \mathrm{~s}^{-1}, 6.2 \times 10^{-15} \mathrm{~m}^{2}\right.$ $\mathrm{s}^{-1}$, and $4.6 \times 10^{-15} \mathrm{~m}^{2} \mathrm{~s}^{-1}$, respectively). The observed differences can be explained by a temperature difference of $10^{\circ} \mathrm{C}$, so it is not significant.

\section{B. The structure of the expanded austenite}

Figure 10 shows some examples of the fitting from different stages of the $420{ }^{\circ} \mathrm{C}$ experiment. The match is not perfect, but the main features of the expanded austenite peak are clearly reproduced, i.e., the sharply rising left flank and the left steep right flank. The fit slightly underestimates the experimental values, but a good general agreement is nevertheless achieved. Unlike Öztürk and Williamson, ${ }^{23}$ we did not carry out physical depth profiling. Accordingly, we opted to use a crude "rule of thumb type" model instead of a more refined one with more degrees of freedom. The general idea is quite simple: the lower angle side of the expanded austenite comes closer to the surface, while the higher angle part belongs to the deeper regions. This has been proven in Ref. 23 and assumed in any composition modelling, e.g., Ref. 11.

Figure 11(a) shows some lattice expansion depth profiles from the $440{ }^{\circ} \mathrm{C}$ processing in the standard depth scale. The diffusion zone extends as the time progresses indeed at the later stages, and it is broader than the here plotted $0-4.5 \mu \mathrm{m}$ range. Similar tendencies can be observed for the $360^{\circ} \mathrm{C}$ [Fig. 10(b)] experiment too, though owing to the slower diffusion the expanded austenite remains completely in the observable range.

More interesting are the rescaled graphs at Figs. 11(c) and 11(d); here, instead of the depth, the Boltzmann-variable

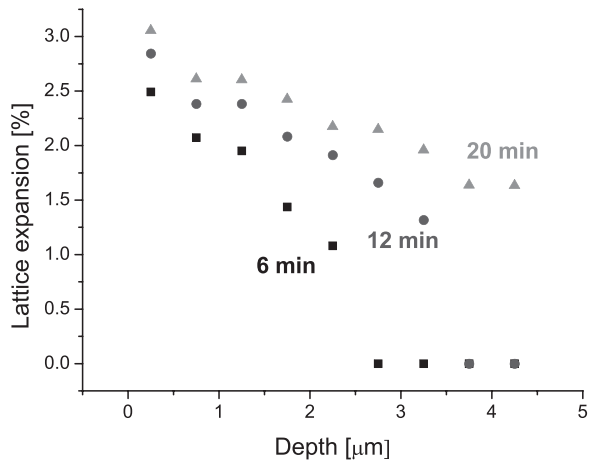

(a)

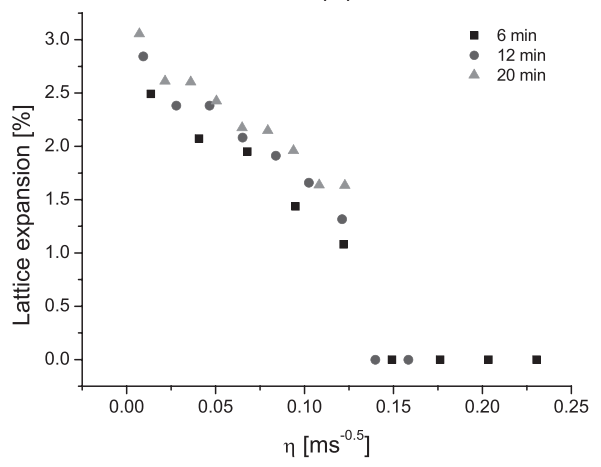

(c)

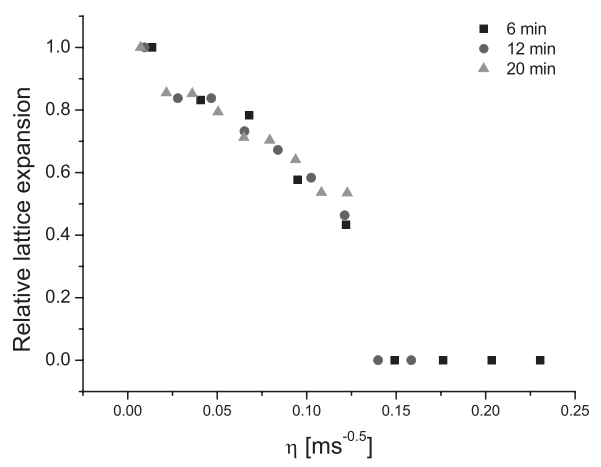

(e)

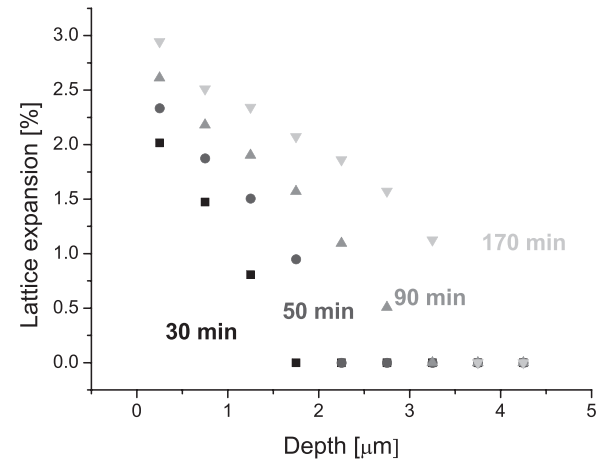

(b)

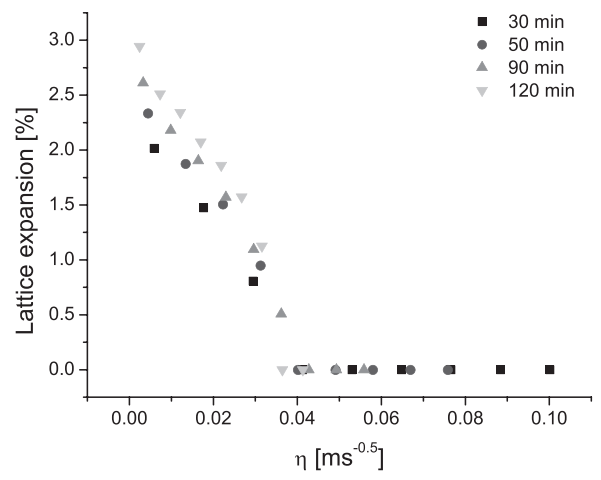

(d)

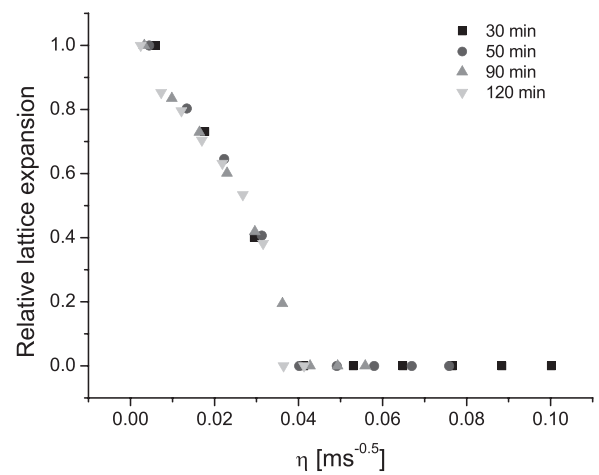

(f)
FIG. 11. The lattice expansion as a function of depth at different times for processing conducted at $440{ }^{\circ} \mathrm{C}$ (a) and $360^{\circ} \mathrm{C}$ (b). The respective profiles after converting to the Boltzmannmetric (c) and (d) and relative to the lattice expansion of the first layer (e) and (f). 
is used as scaling parameter. Here, the width of the diffusion zone is practically constant for each experiment, though the overall lattice expansion increases with time. In Figs. 11(e) and 11(f), another normalizing step is included; the lattice expansions are scaled by the values of the first sublayer. After that step, the curves during a given experiment are nearly identical.

How these results can be interpreted? According to the assumption in 3.2, the lattice expansion vs the Boltzmannvariable plot can be interpreted as an interstitial concentration vs the Boltzmann-variable plot.

The fact that the width of the diffusion zone is constant in the Boltzmann-metric indicates that the broadening of the expanded austenite is controlled by the diffusion of the interstitial species. That the composition profile does not look like an error function profile is well understandable from the fact that the diffusion coefficient is concentration dependent. ${ }^{7}$ In such cases, high diffusivity zones have low concentration gradients, while low diffusivity zones are characterized by high gradients. Based on the results of Ref. 7, the diffusion is the slowest at low interstitial concentrations; hence, one can expect high gradients at the expanded austenite/base material interface. This is in accordance with our results. Furthermore, the diffusivity changes only mildly (by a factor of 2) for a high interstitial concentration. Thus, the minor change of the gradient within the expanded austenite is again in agreement with the expectations.

Finally, the continuous increase of the lattice expansion at the first layer deserves some thoughts. This can be a sampling effect, i.e., as the diffusion zone expands the average concentration in the first $0.5 \mu \mathrm{m}$ increases; however, Fig. 6(b) suggests that there is a real shift of the right hand side edge towards lower angles. This means that the surface concentration of the interstitials increases with time. Since our plan was to follow the evolution of the $\gamma$-Fe 111 peak, we stopped our experiments before the saturation was reached.

In summary, the evolution of the expanded austenite is driven by two processes, diffusion within the layer (the low concentration side limits the process) distributes the N/C interstitials in order to achieve composition gradients required by the concentration dependence of the diffusion coefficient. In parallel to this, the surface concentration of N/C increases and this leads to a general increase in the concentration of the interstitials within the layer. The uptake of the $\mathrm{N} / \mathrm{C}$ might also limit the growth of the layer at the very beginning (see Fig. 7).

\section{CONCLUSIONS AND OUTLOOK}

We carried out thermochemical nitrocarburizing of AISI 316L stainless steel specimens in a custom designed XRD furnace and observed the development of the expanded austenite phase in-situ. This novel setup allows the study of kinetics of the growth of expanded austenite through nitriding, carburizing, or nitrocarburizing. The total thickness of the expanded austenite layer was determined from the attenuation of the $\gamma$-Fe peak. The growth rate coefficient was evaluated in the framework of the linear-parabolic equation. This allowed us to reduce the supply/nucleation related artefacts. The activation energy of the growth reaction is $165 \pm 12 \mathrm{~kJ} / \mathrm{mol}$ which is in an adequate agreement of literature data derived from plasma nitriding.

Based on the information on the total layer thickness, the peak belonging to expanded austenite can also be fitted as a sum of multiple Gaussian peaks. Plotting the lattice expansion as a function of the Boltzmann-variable $\left(\eta=0.5 x t^{-1 / 2}\right)$, the expanded austenite has a constant thickness. By scaling the curves with the lattice expansion of the first sublayer, a time-independent master curve can be obtained. This suggests that the broadening of the layer is controlled by the diffusion within the expanded austenite, while the exact value of the lattice expansion is set by the uptake of interstitial at the solid/gas interface. This more detailed analysis suggests that a single interdiffusion coefficient model is indeed valid on the large scale.

The here presented concept of X-ray in-situ studies allows systematic investigations of steel surface treatments using reactive gases. Steel processing and finishing is still a hot topic in many application areas and materials and process understanding helps in designing new and optimized industrial procedures.

In the future, we will extend these investigations in two directions. First, we will carry out $e x$-situ stress measurements on selected specimens. Second, we will carry out physical depth profiling; thus, we can determine the lattice parameter as a function of time and depth with higher precision.

\section{SUPPLEMENTARY MATERIAL}

See supplementary material for the attenuation coefficients as a function of the X-ray energy for three alloys: base austenite, $\mathrm{C}$ - and $\mathrm{N}$-expanded austenite. Diffractograms of various as-received specimens. The indexed peaks in one selected specimen in the as-received samples. The evolution of the diffractogram at $360^{\circ} \mathrm{C}$. The evolution of the diffractogram at $440^{\circ} \mathrm{C}$.

${ }^{1}$ Z. L. Zhang and T. Bell, Surf. Eng. 1, 131 (1985).

${ }^{2}$ K. Ichii, K. Fujimura, and T. Takase, Technol. Rep. Kansai Univ. 27, 135 (1986), ISSN:0453-2198.

${ }^{3}$ D. L. Williamson, O. Öztürk, R. Wei, and P. J. Wilbur, Surf. Coat. Technol. 65, 15 (1994).

${ }^{4}$ T. Christiansen and M. A. J. Somers, Scr. Mater. 50, 35 (2004).

${ }^{5}$ D. Manova, S. Mändl, H. Neumann, and B. Rauschenbach, Surf. Coat. Technol. 256, 64 (2014).

${ }^{6}$ D. Wu, Y. Ge, H. Kahn, F. Ernst, and A. H. Heuer, Surf. Coat. Technol. 279, 180 (2015).

${ }^{7}$ T. Christiansen and M. A. J. Somers, Int. J. Mater. Res. 99, 999 (2008).

${ }^{8}$ J. Buhaigar, H. Dong, and T. Bell, Surf. Eng. 23, 313 (2013).

${ }^{9}$ C. Blawert, B. L. Mordike, G. A. Collins, K. T. Short, Y. Jirásková, O. Schneeweiss, and V. Perina, Surf. Coat. Technol. 128-129, 219 (2000).

${ }^{10}$ X. Y. Li, J. Buhaigar, and T. Bell, Surf. Eng. 26, 67 (2010).

${ }^{11}$ T. Christiansen, K. V. Dahl, and M. A. J. Somers, Mater. Sci. Technol. 24, 159 (2008).

${ }^{12}$ A. Martinavičius, G. Abrasonis, A. C. Scheinost, R. Danoix, F. Danoix, J. C. Stinville, G. Talut, C. Templier, O. Liedke, S. Gemming, and W. Möller, Acta Mater. 60, 4065 (2012).

${ }^{13}$ T. Christiansen and M. A. J. Somers, Metall. Mater. Trans. A 37, 675 (2006).

${ }^{14}$ T. Moskalioviene, A. Galdikas, J. P. Rivière, and L. Pichon, Surf. Coat. Technol. 205, 3301 (2011). 
${ }^{15}$ D. Manova, S. Mändl, J. W. Gerlach, D. Hirsch, H. Neumann, and B. Rauschenbach, J. Phys. D: Appl. Phys. 47, 365301 (2014).

${ }^{16}$ F. M. d'Heurle and P. Gas, J. Mater. Res. 1, 205 (1986).

${ }^{17}$ B. E. Deal and A. S. Grove, J. Appl. Phys. 36, 3770 (1965).

${ }^{18}$ T. Christiansen and M. A. J. Somers, Int. J. Mater. Res. 100, 1361 (2009).

${ }^{19}$ E. J. Mittemeijer and M. A. J. Somers, Surf. Eng. 13, 483 (1997).

${ }^{20}$ B. Parditka, M. Verezhak, Z. Balogh, A. Csik, G. A. Langer, D. L. Beke, M. Ibrahim, G. Schmitz, and Z. Erdélyi, Acta Mater. 61, 7173 (2013).

${ }^{21}$ U. Gösele and K. N. Tu, J. Appl. Phys. 53, 3252 (1982).

${ }^{22}$ D. L. Williamson, J. A. Davis, P. J. Wilbur, J. J. Vajo, R. Wei, and J. N. Matossian, Nucl. Instrum. Methods Phys. Res., Sect. B 127-128, 930 (1997).

${ }^{23}$ O. Öztürk and D. L. Williamson, J. Appl. Phys. 77, 3839 (1995).

${ }^{24}$ L. Boltzmann, Ann. Phys. 289, 959 (1894).
${ }^{25}$ Z. Erdélyi, D. L. Beke, P. Nemes, and G. A. Langer, Philos. Mag. 79, 1757 (1999).

${ }^{26}$ Z. Balogh and G. Schmitt, "Diffusion in metals and alloys," in Physical Metallurgy, edited by D. E. Laughlin and K. Hono (Elsevier, Amsterdam, 2014), Vol. 5. Chap. 5.7.1, pp. 525-535.

${ }^{27}$ F. N. Jespersen, J. H. Hattel, and M. A. J. Somers, Modell. Simul. Mater. Sci. Eng. 24, 025003 (2016)

${ }^{28}$ Z. Erdélyi, B. Parditka, and D. L. Beke, Scr. Mater. 64, 938 (2011).

${ }^{29}$ R. P. Smith, Trans. AIME 230, 476 (1964), ISSN: 0543-5722.

${ }^{30}$ P. Thibaux, A. Métenier, and C. Xhoffer, Metall. Mater. Trans. A 38, 1169 (2007).

${ }^{31}$ J. Agren, Acta. Metall. 20, 1507 (1986).

${ }^{32}$ H. K. D. H. Bhadesia, Met. Sci. 15, 477 (1981). 